\title{
Ciganos e Itinerância Realidades Concelhias e Formas de Hospitalidade
}

Alexandra Castro*

\begin{abstract}
$\mathrm{R}$ Resumo: Em Portugal, como em grande parte dos países europeus, a falta de dados actualizados sobre a população cigana e com um nível de desagregação territorial elevado tem dificultado o delinear de políticas públicas, locais ou nacionais. Um estudo recentemente concluído permitiu identificar a dimensão da comunidade cigana em grande parte do território continental; os locais de permanência dos ciganos itinerantes e razões para a alteração dos espaços de fixação; as reaç̧ões "formalizadas" da população local face à presença dos ciganos; e a existência de locais específico para acolher populações itinerantes. Apresentam-se aqui estes resultados, procurando reflectir no final sobre as potencialidades que apresentam as áreas de acolhimento quer como uma resposta inovadora à problemática da habitação para populações desfavorecidas quer como um direito dos itinerantes.
\end{abstract}

Palavras-Chave: ciganos; itinerância; áreas de acolhimento; coexistência inter-étnica

A falta de dados sobre a população cigana não é específica a Portugal, mas a grande parte dos países europeus. Existe muitas vezes a ideia que a recolha deste tipo de informação viola a lei de protecção de dados. No entanto, a União Europeia tem vindo a afirmar que as regras de protecção de dados se aplicam a dados pessoais e não a dados de conjunto que digam respeito a grupos ou a dados recolhidos tendo por base o critério étnico ou outros ${ }^{1}$.

Esta ausência de dados tende a limitar a concepção, acompanhamento e avaliação de políticas e programas relativas à inclusão social. Decisores e políticos vêem, assim, a sua base de acção limitada, na medida em que não podem sustentá-la de forma clara. Mas, sobretudo, esta ausência sistemática de informação faz com que se tenha muitas vezes um conhecimento distorcido da realidade pelas imagens que o senso comum vai deixando passar: a grande visibilidade que algumas famílias têm em determinados territórios não significa necessariamente uma forte presença de população cigana.
No sentido de colmatar a ausência deste tipo de dados actualizados, considerou-se fundamental, no âmbito de um projecto de investigação recentemente concluído ${ }^{2}$, recolher informação junto das câmaras municipais do continente, através do envio do questionário Ciganos, Territórios e Itinerância (CTI). O único recenseamento conhecido a nível de Portugal continental foi realizado em 1997 pelo SOS Racismo, no âmbito do Grupo de Trabalho para a Igualdade e Inserção dos Ciganos do Alto Comissário para as Minorias Étnicas, mas apenas publicado em 2001. Por outro lado, revelou-se igualmente importante ter um panorama mais geral sobre a situação dos ciganos itinerantes no continente e algumas práticas que visam esta comunidade em particular. No sentido de se complementar a informação recolhida através do questionário CTI, foi enviado por correio electrónico um questionário semelhante aos 18 Governadores Ci$v^{3}{ }^{3}$. Para $o$ aprofundamento de algumas das questões optou-se por uma estratégia mais intensiva e qualitativa de recolha e análise da informação.

\footnotetext{
* Socióloga, Investigadora do CET. Contacto: castro.alexandra@gmail.com

' Para um maior aprofundamento desta questāo poderá consultar-se o Regulamento (CE) n.• 45/2001 do Parlamento Europeu e do Conselho de 18 Dezembro de 2000 .

2 Duarte, I.; Afonso, Joana; Afonso, Joāo; Castro, Alexandra; Soares, Luís (2005). Os ciganos vistos pelos outros: proximidade social em espaços de coexistência inter-étnica, Lisboa, CET/FCT. Investigaçāo financiada pela Fundaçāo para a Ciência e Tecnologia (SAPIENS/ /POCTI).

3 Apenas foram recepcionadas 3 respostas: Leiria, Faro e Viseu, embora este último nāo tenha procedido ao preenchimento do questionário por não dispor de "dados tão circunstanciados sobre a realidade em causa", remetendo para outras entidades a possibilidade de existir a informaçāo solicitada.
} 


\section{O Questionário Ciganos, Territórios e Itinerância e o Problema das Fontes}

O questionário CTI tinha como objectivos conhecer a dimensão da comunidade cigana (itinerante e sedentarizada), os locais de permanência dos ciganos itinerantes e razões para a alteração dos espaços de fixação, as reacções "formalizadas" da população local face à presença dos ciganos e a existência de um local específico para acolher populações itinerantes.

O questionário foi enviado, via postal, às 278 câmaras municipais do continente, tendo-se conseguido obter $55 \%$ de respostas. Esta taxa relativamente elevada poderá estar relacionada com a necessidade das próprias autarquias em conhecer a realidade existente noutros municípios, mas também por se terem agilizado processos de diagnóstico concelhios em determinadas áreas sociais.

Das 124 câmaras que não responderam ao questionário, foi possível colmatar a ausência de informação através dos dados recolhidos pelo SOS Racismo para 44 concelhos do país. De referir que 64 câmaras municipais foram reincidentes nas Não Respostas $^{4}$ e 16 referiram, em ambos os questionários, não existirem ciganos ou não disporem de dados $^{5}$. Embora reconhecendo-se que a presença dos ciganos em determinados concelhos possa já não corresponder à realidade existente, optou-se por apresentar os dados, incluindo os tais 44 concelhos que não tendo respondido ao questionário CTI, responderam ao do SOS Racismo. Os dados que se apresentam face à dimensão da comunidade cigana correspondem, então, a 182 concelhos do continente, ou seja, obtém-se uma cobertura de $65,5 \%$ do território continental. Existe, assim, uma aproximação mais fiável à realidade existente no continente, embora nunca traduza a real expressão da presença dos ciganos, dado o problema das fontes a que a maioria das vezes se recorre para contabilizar o número de ciganos. Deve salientar-se que o tempo que medeia a aplicação dos dois questionários levanta restrições à actualidade dos dados recolhidos pelo SOS Racismo. De referir os distritos de Beja, Porto, Leiria e Bragança por apresentarem as taxas mais elevadas de resposta (entre $75 \%$ e $86 \%$ ), ao passo que os distritos de Vila Real, Coimbra e Viana do Castelo registam os valores mais baixos, respectivamente com $21,4 \%, 47,1 \%$ e $50 \%$.

Relativamente aos concelhos que foram reincidentes nas Não Respostas em ambos os questionários poder-se-á estar perante distintas situações que ocorrem nos concelhos ou nas próprias autarquias. Independentemente das razões que poderão estar por detrás desta ausência sistemática de informação, seria importante conhecer a realidade destes municípios no que toca à comunidade cigana, pois em alguns destes casos o conhecimento empírico revela uma forte presença de elementos da etnia cigana nos territórios em questão e/ou problemas de coexistência social que mereceriam uma atenção especial.

Refira-se a título de exemplo o caso de Vila Nova de Poiares já citado num anterior estudo ${ }^{6} \mathrm{em}$ que a Câmara Municipal emitiu um comunicado (29-02-2000), segundo o qual se pretendia impedir a presença de 'indesejáveis' (grupos étnicos ou nómadas) no concelho, prontificando-se a colaborar com os habitantes na identificação dos "forasteiros" que pretendiam instalar-se em Poiares. De acordo com o Expresso, o que parece ter dado origem a este comunicado foi o arrendamento de um apartamento a uma família cigana de fora do concelho (Expresso, 18-03-2000).

Caso as fontes de recolha de informação utilizadas pelas autarquias em ambos os questionários fossem as mesmas seria possível fazer uma aproximação aos processos em curso no território continental, no que diz respeito à evolução da presença dos ciganos por concelho e distrito. No entanto, o desconhecimento dos procedimentos adoptados pelos municípios que responderam ao questionário do SOS Racismo e pela ausência desta informação em alguns dos questionários CTI impede esta comparação.

\footnotetext{
4 Águeda, Espinho, Mealhada, S. João da Madeira, Sever do Vouga, Vale de Cambra; Ferreira do Alentejo e Ourique; Amares e Terras do Bouro; Boticas, Miranda do Corvo, Torre de Moncorvo, Vimioso e Vinhais; Belmonte, Castelo Branco, Penamacor; Figueira da Foz, Soure, Tábua, Vila Nova de Poiares; Mourão, Vendas Novas e Viana do Alentejo; Alcoutim, Faro, Olhão; Figueira de Castelo Rodrigo, Guarda, Meda, Seia, Trancoso; Ansião, Óbidos, Pedrógão Grande, Peniche; Lisboa, Loures, Oeiras, Sintra e Sobral de Monte Agraço; Alter do Chão, Arronches, Avis, Campo Maior e Sousel; Baião, Maia e Penafiel; Abrantes, Chamusca e Tomar Santiago do Cacém; Arcos de Valdevez e Valença; Alijó, Peso da Régua, Ribeira de Pena, Sabrosa, Vila Pouca de Aguiar e Vila Real; Armamar, Carregal do Sal, Vila Nova de Paiva e Viseu.

5 Dois concelhos do distrito de Aveiro (Arouca e Vale de Cambra), um de Beja (Alvito), quatro de Braga (Cabeceiras de Basto, Celorico de Basto, Vieira do Minho e Vizela), um de Coimbra (Góis), um de Évora (Mora), dois da Guarda (Fornos de Algodres e Manteigas), um de Leiria (Alvaiázere), um de Viana do Castelo (Caminha), um de Vila Real (Montalegre), dois de Viseu (Oliveira de Frades e Resende).

${ }^{6}$ Cf. Duarte, I. (2000).
} 
De referir, que os municípios que indicaram as fontes utilizadas para recensear o número de ciganos existentes por concelho indicaram maioritariamente que recorreram à sinalização ou ao acompanhamento que diversas entidades fazem a esta população, podendo assim a realidade retratada ficar aquém da verdadeira expressão concelhia desta comunidade. As fontes utilizadas assentam, sobretudo, em dados recolhidos no âmbito de práticas de realojamento da responsabilidade dos respectivos municípios. No caso de outras entidades serem as responsáveis pelo realojamento, não foram disponibilizados os dados das famílias ciganas alvo deste tipo de intervenção, estando, assim, a expressão desta população em determinados municípios subestimada (o concelho da Amadora é um dos exemplos desta situação). Por outro lado, a ausência de dados para algumas capitais de distrito, tais como Castelo Branco, Évora, Faro, Guarda, Lisboa, Vila Real e Viseu, tende de igual forma a condicionar a apresentação dos resultados. As juntas de freguesia, as forças de segurança pública, a segurança social, foram também outras entidades a que mais se recorreu para obter dados, mas também alguns projectos em curso em que a população cigana é beneficiária (foi o caso, por exemplo, de alguns projectos em curso nos municípios de Aveiro, Fundão e Nazaré).

Os dados disponibilizados estão, ainda, condicionados pelo departamento da câmara que procedeu ao seu preenchimento. Constatou-se, em algumas situações, não existir articulação entre os vários departamentos para o preenchimento, nomeadamente entre os responsáveis pelo sector da habitação e da acção social. Verificou-se também que o Programa Rede Social, no âmbito dos diagnósticos que elabora foi ou virá a ser, igualmente, uma fonte relevante para um maior conhecimento da população cigana.

\section{A Expressão dos Ciganos em Portugal Continental}

Salvaguardando que 96 concelhos não disponibilizaram informação ou não responderam ao questionário e que grande parte dos dados recolhidos não podem ser considerados exaustivos, são cerca de 20 mil os ciganos existentes no continente. De referir que outros estudos ${ }^{7}$ têm apontado para a existência em Portugal de cerca de 50 mil ciganos (Fig. 1).

De acordo com os dados recolhidos, o distrito do Porto é o que concentra o maior número absoluto de ciganos (2268), seguido dos distritos de Lisboa (1882), Faro (1688), Braga (1566) e Aveiro (1536). O valor do distrito de Lisboa estará aqui com certeza subestimado pela ausência de dados da capital do país. De referir que no âmbito de um estudo da Pastoral dos Ciganos (Marques, Correia, Reis, 1996), o concelho de Lisboa contava com 2332 e o distrito com 5640 , situação que alteraria o panorama que aqui se está a apresentar.

Braga como o $4 .^{\circ}$ distrito com maior concentração de ciganos foi o único em que das 9 câmaras que responderam ao questionário CTI, nenhuma delas indicou o número de ciganos ora por não existirem de facto, ora porque não dispunham de dados. Assim, embora a taxa de resposta seja das mais elevadas do continente $(71,4 \%)$, os dados apresentados dizem respeito apenas a 4 concelhos que responderam ao questionário do SOS Racismo. Os restantes distritos apresentam valores inferiores a 1500 ciganos, sendo Vila Real aquele que regista o valor mais baixo (180), valor muito condicionado pela baixa taxa de resposta $(21,4 \%)$.

$\mathrm{O}$ distrito de Leiria com uma taxa de resposta relativamente elevada (75\%) regista a presença de 830 ciganos, não havendo informação para 4 concelhos (Ansião, Óbidos, Pedrógão Grande, Peniche). A disponibilização desta informação iria concerteza ao encontro do número apontado pelo gabinete do Governador Civil deste distrito que aponta para mais de 1200 ciganos sedentarizados.

Fig.1 - Distribuição do número de ciganos por distrito

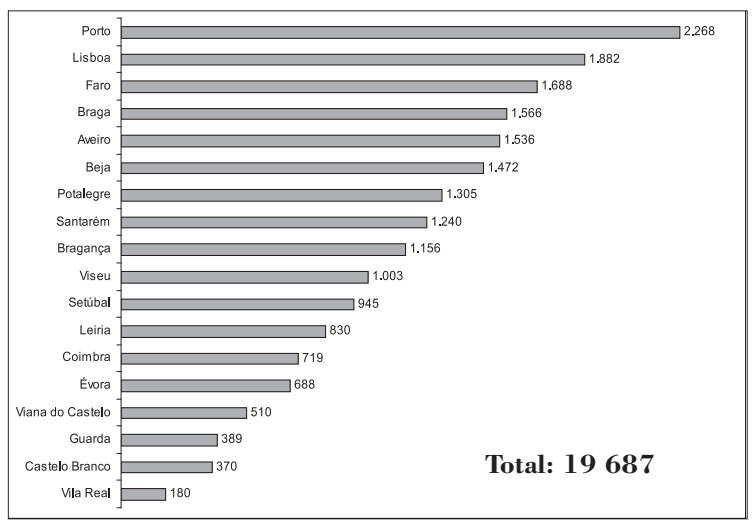

Fonte: Questionário Ciganos, Territórios e Itinerância, CET, 2005 e SOS Racismo, 1997

\footnotetext{
${ }^{7}$ Cf., nomeadamente, Machiels, 2002: 11.
} 
Constata-se que 30 municípios referem não existir ciganos, estando estes concelhos distribuídos por 13 dos 18 distritos ${ }^{8}$. Para além destes, os concelhos que registam valores entre 2 e 10 ciganos são: Castro Marim (2), Fronteira (2), Penedono (3), Santa Comba Dão (3), Batalha (4), Castelo de Vide (4), Sertã (4), Cantanhede (5), Almodôvar (6), Vila Velha de Ródão (6), Aljezur (7), Castro Daire (8), Sardoal (8), Freixo de Espada à Cinta (9), Anadia (10), Barrancos (10), Redondo (10). Por seu lado, os concelhos com mais ciganos são: Braga (1000), Elvas (800), Loulé (558), Coimbra (500), Lamego (500), Porto (500), Vila Nova de Gaia (494), Coruche (490), Viana do Castelo (480) e Aveiro (413).

Uma análise da distribuição dos ciganos pelo território continental permite constatar claramente os seguintes aspectos:

- a existência de um corredor no interior do país correspondente a concelhos que não têm disponibilizado informação sobre a presença dos ciganos nos respectivos territórios;

- a existência de uma linha que parece delinear-se a partir do concelho de Vila de Rei para Norte traduzida por autarquias que tendem a não registar a presença de ciganos. Muitos destes concelhos são contíguos revelando-se pertinente em futuras investigações conhecer as razões da não permanência de ciganos nestes territórios. Esta necessidade justifica-se, sobretudo, por alguns destes concelhos fazerem fronteira com outros que registam uma forte presença de ciganos (a título de exemplo refira-se o caso de Penacova que faz fronteira com Coimbra);

- Alvito aparece como o único concelho da região do Alentejo que tendo disponibilizado informação referiu que apenas existem itinerantes;

- Se os ciganos se tendem a fixar no litoral, área de grande concentração populacional, não deixa de ser relevante a sua presença em concelhos que fazem fronteira a Este com Espanha.

A distribuição do peso dos ciganos face à população residente no continente oferece um outro panorama. Se a expressão desta população representa $0,2 \%$, o distrito de Portalegre surge no topo do ranking dos distritos com maior concentração desta população com 1\%, seguido de Beja $(0,9 \%)$, Faro $(0,4 \%)$ e Évora $(0,4 \%)$. São, assim, sobretudo, as regiões do Alentejo e Algarve onde a população cigana assume o maior peso face à não cigana.

Fig. 2 - Distribuição do peso dos ciganos face à população residente por distrito (\%)

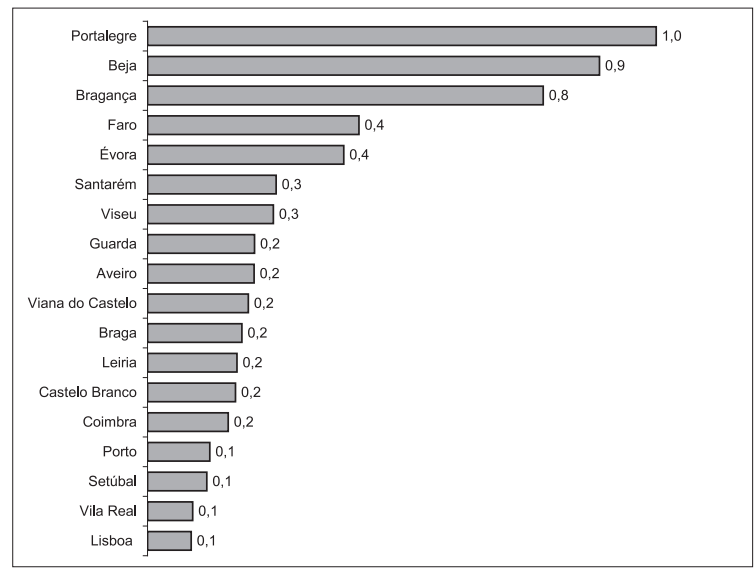

Fonte: Questionário Ciganos, Territórios e Itinerância, CET, 2005 e SOS Racismo, 2001

Os concelhos que não chegam a atingir $0,1 \%$ face à população residente são: Cantanhede, Oliveira de Azeméis, Sertã, Santa Comba Dão, Batalha, Lousada, Castro Marim, Anadia, Amarante, Ponte de Lima, Ourém, Trofa, Palmela, Castro Daire. Por seu lado, aqueles que apresentam um peso superior a $2 \%$ de ciganos face à população residente: Vidigueira $(2,1 \%)$; Nisa $(2,1 \%)$, Mogadouro $(2,2 \%)$, Estremoz (2,2\%), Coruche $(2,3 \%)$, Cuba $(2,6 \%)$, Idanha-a-Nova $(2,7 \%)$, Elvas $(3,4 \%)$ e Monforte (5\%).

\section{Os Ciganos Itinerantes: Necessidade de se Enfatizar ou Ocultar a sua Expressão}

Uma das questões procurava captar o peso dos ciganos itinerantes face aos sedentarizados? Optou-se por não se explicitar o que se entendia

\footnotetext{
${ }^{8}$ Três do distrito de Aveiro (Arouca, Castelo de Paiva, Vale de Cambra), um de Beja (Alvito), três de Braga (Celorico de Basto, Esposende, Póvoa de Lanhoso), dois de Castelo Branco (Oleiros e Vila de Rei), três de Coimbra (Arganil, Pampilhosa da Serra, Penacova), três da Guarda (Aguiar da Beira, Fornos de Algodres, Manteigas), três de Leiria (Alvaiázere, Castanheira de Pêra, Marinha Grande), um de Lisboa (Alenquer), um de Setúbal (Alcochete), dois de Viana do Castelo (Caminha e Melgaço), um de Vila Real (Montalegre), quatro de Viseu (Mortágua, Oliveira de Frades, Penalva do Castelo, Resende), três de Braga (Barcelos, Cabeceiras de Basto, Vieira do Minho).

9 Houve municípios que incluíram nos sedentarizados os itinerantes, e outros que optaram por fazer esta distinção. Foi o caso, por exemplo, de Alvito que indicou não existirem membros, mas referiu que $100 \%$ dos ciganos do concelho são itinerantes.
} 
por itinerante para compreender as representações subjacentes a esta noção por parte dos municípios. Os resultados apurados permitem constatar uma grande diversidade de entendimentos sobre esta questão ${ }^{10}$.

Por um lado, houve municípios que não conseguiram identificar o peso dos ciganos itinerantes, mas referem a sua circulação pelo concelho em ocasiões festivas da própria comunidade (casamentos e baptizados) e de feiras e festas locais para o exercício da sua actividade comercial. Por outro lado, houve aqueles que referiram não existir ciganos itinerantes embora indiquem que em determinados momentos circulam e permanecem no território concelhio ciganos.

De salientar um caso em que apesar de se identificar o peso dos ciganos itinerantes se referiu não existir no “(...) concelho população de etnia cigana itinerante pelo que as famílias ciganas estão praticamente integradas na nossa comunidade, apenas em épocas de feira ou mercados municipais esta população aparece não permanecendo mais do que 2 dias". Apesar da fraca expressividade dos itinerantes (1\%), esta autarquia parece ter sido das primeiras a concretizar um projecto para acolhimento de ciganos que se deslocam ao concelho por ocasião das três feiras anuais nos meses de Janeiro, Maio e Agosto.

Existem situações que podem ser reveladoras de quanto se pode subestimar (intencionalmente ou não) uma realidade existente, mesmo que não tenha muita expressão. É o caso de uma autarquia ao referir que "As famílias ciganas residentes neste concelho habitam em alojamentos normais. Em 1998 quando houve a atribuição de habitações sociais as famílias residentes em barracas foram todas alojadas". No entanto, pelo conhecimento que se tem do concelho constata-se a existência de uma zona com barracas onde vivem ciganos. Outros levantamentos efectuados têm revelado que o ocultar corresponde muitas vezes a práticas normativas que vão contra as liberdades individuais, sendo às vezes mais importante o que ficou por dizer, ou seja, as respostas que não foram dadas (Steinberger et al., 2002, SOS Racismo, 2001: 9).

Foram apenas 43 os municípios que identificaram a percentagem de ciganos itinerantes que circu- lam pelos seus territórios face aos que se encontram sedentarizados. Na maioria destes concelhos os ciganos itinerantes não chegam aos $25 \%$. Apenas em $30 \%$ deles o seu peso pode atingir mais de $50 \%$, ou seja, em concelhos como Albergaria-a-Velha, Alcácer do Sal, Aljustrel, Almeirim, Alvito, Arouca, Beja, Cuba, Macedo de Cavaleiros, Marco de Canaveses, Pinhel, Trofa e Vila Real de Santo António.

Fig. 3 - Peso dos ciganos itinerantes

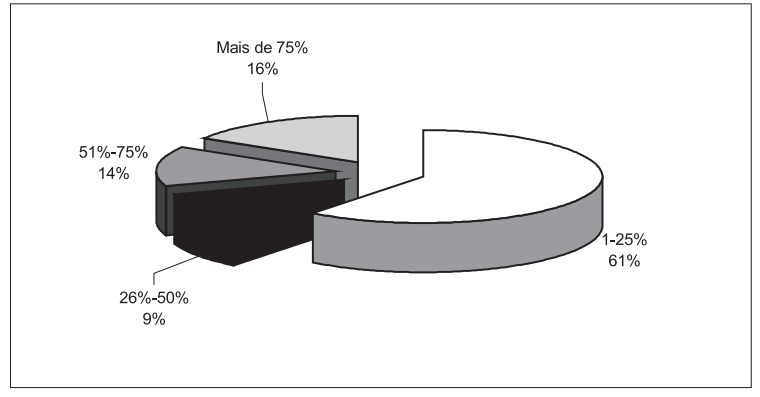

Fonte: Questionário Ciganos, Territórios e Itinerância, CET, 2005

\section{Representações sobre a Itinerância, a Fixação e as Expectativas dos Ciganos face à Casa}

Num estudo anteriormente realizado ${ }^{11}$ constatou-se que os traços negativos associados aos ciganos tendem a ser mais marcantes entre os ciganos nómadas, já que para os entrevistados os ciganos que se sedentarizaram são "mais evoluídos", "mais sociáveis", ao passo que os nómadas têm poucas preocupações relativas à manutenção do espaço onde habitam e à higiene pessoal. Era, assim, importante perceber no âmbito dos interlocutores da presente pesquisa, com características sócio-profissionais diferentes e, sobretudo, com experiência de trabalho com a comunidade cigana se esta representação se mantinha.

Constatou-se, assim, através das entrevistas realizadas que a itinerância surge sempre como um traço cultural da comunidade cigana, independentemente do grau de fixação dos seus membros a determinado território, das expectativas que revelam face à casa e da temporalidade e motivos dos seus percursos.

Esta característica dos ciganos que os "impede" de estar permanentemente no mesmo lugar

\footnotetext{
${ }^{10}$ Estas diferenças foram passíveis de captar através de um cruzamento entre o peso de itinerantes indicado pelos municípios e as observações que registaram num espaço reservado para o efeito. Muitas autarquias consideraram importante explicitar no referido espaço, entre outros aspectos, que tipo de presença os itinerantes tinham no território concelhio.

11 Duarte, I. (2000).
} 
justifica-se, segundo os entrevistados, como uma "estratégia de sobrevivência" para concretizarem actividades profissionais no âmbito da economia formal, informal ou subterrânea, mas também para gerirem de uma forma mais eficaz os conflitos gerados no interior da comunidade cigana ou com outras populações. As visitas a familiares hospitalizados ou presos é também outra razão apontada para a deslocação dos ciganos a concelhos com este tipo de equipamentos.

Parece ser unânime a ideia da existência de ciganos que se encontram permanentemente em circulação, apontando-se para um "nomadismo sazonal" e conjuntural que pressupõe um retorno a um mesmo lugar, independentemente das condições habitacionais que aí possam encontrar. De facto, no caso dos ciganos, nomadismo e sedentarização não devem ser entendidos como conceitos mutuamente exclusivos, traduzindo "modos de vida conjunturais" que respondem a factores internos e externos à dinâmica social cigana (Castro 1995; San Roman, 1997; Sama, 2003).

Num estudo anteriormente realizado constatámos (Castro, 1994) que os próprios ciganos tendem a reconhecer os factores acima identificados pelos entrevistados, no entanto, acrescentam a importância da viagem como uma oportunidade para desenvolverem o seu capital relacional - elemento importante para se socorrerem quando atravessam alguma dificuldade -, ao mesmo tempo que obtêm informações e as fazem circular. Mas também identificam uma variável externa ao grupo: a pressão policial perante o estacionamento de populações ciganas em determinadas áreas ${ }^{12}$.

A representação da itinerância como um traço cultural poderá assumir aspectos mais ou menos positivos consoante a posição que se privilegia face à abordagem da inserção vista esta numa perspectiva que incide mais na multiculturalidade ou na aculturação. As preocupações de gestão sócio-territorial não deixam também de estar presentes. Assim, encontra-se a associação da itinerância a liberdade mas também a desvio.
É possível encontrar no pólo positivo uma componente mistificadora e romântica da mobilidade espacial, como sinónimo da liberdade individual ou grupal. Mas valorizar este aspecto parece também, em alguns casos, dar a entender que a sua itinerância lhes retira qualquer vínculo territorial e de acesso a direitos e que qualquer estratégia desencadeada pelos ciganos com vista à fixação tende para uma ocupação abusiva do espaço (como a construção de barracas) ou para beneficiar de determinadas medidas de protecção social (como o Rendimento Social de Inserção) ou de acesso a determinados serviços:

"A ideia ainda muito presente nos técnicos de determinados serviços é de que se procuram procuram, se não procurarem ainda bem que é menos um que aparece."

(Técnica de serviço social numa Câmara Municipal)

E referindo-se a uma medida de política social concreta, a mesma entrevistada adianta:

"Sabemos aqui nos serviços que só passou a existir uma maior fixação dos ciganos a partir do momento que foi criado o Rendimento Mínimo Garantido. Neste mesmo bairro notamos a evolução desde 1997 do crescimento estrondoso de barracas a fixarem-se aí e pediram declarações à junta de freguesia em como eram residentes. E a junta durante um período passou..., quando afinal não eram nada residentes (...) foi-lhes dado um chupa-chupa para que eles se fixassem. No fundo, isso contraria tudo o que é a rotina deles e que eles contornam sabiamente."

Por outro lado, menciona ainda o descrédito dos técnicos de acção social sobre o envolvimento com sucesso dos ciganos em programas de inserção, como se a integração na sociedade maioritária fosse completamente impossível:

Outra entrevistada embora reconhecendo que cada vez mais os ciganos tendem a ter uma maior apetência pela ligação a um determinado local que lhes permita o retorno e as condições de conforto necessárias, relativiza a sua relação com a casa pela importância que assume a itinerância nos seus modos de vida:

\footnotetext{
${ }^{12}$ Um testemunho cigano recolhido no âmbito desta pesquisa é revelador desta situação “(...) nós noutro tempo éramos uns escravos, escravos da autoridade, escravos dentro de uma polícia, dentro de uma cidade, escravos por um monte, nós ficávamos assim a uma estrema, não parávamos, chegava um qualquer de uma propriedade, até com as panelas do comer ao lume tínhamos que abalar, não nos consentiam, onde é que a gente dormia? vivíamos no ar?... hoje podemos em todas as terras tar 24 horas..., noutro tempo não era assim, noutro tempo éramos uns escravos, não sei se compreende? Mas era no tempo do Salazar, no tempo do Salazar, mas desde que entrou outro governo cá a coisa modificou logo, a maneira já foi outra (...)" (Castro, 1994)
} 
"Se tiverem que escolher entre a casa e o carro é o carro que escolhem, ele é uma ferramenta de trabalho para transportar a mercadoria, porque às vezes tem de se ir buscar muito longe, para irem a casamentos, a funerais, ou porque podem ter que fugir, a carrinha são as suas pernas e de um momento para o outro pode ter que se transformar na sua casa."

(Antropóloga, técnica superior numa Câmara Municipal)

A relação dos ciganos com a casa é, sobretudo, valorizada pela manutenção que fazem do habitat. As ideias de "limpeza", "brilho", "brancura", "arrumação" parecem surpreender e contrariar imagens que alguns dos técnicos tinham antes de iniciarem um contacto mais próximo e regular com ciganos:

"A primeira vez que eu entrei numa barraca fiquei espantadíssima, porque é de uma limpeza extrema, não é essa a imagem que nós, de fora, temos desse tipo de pessoas, temos um pouco a imagem que eles não são asseados, muito sujos, mas é precisamente o contrário e fiquei muito espantada quando vi os edredões muito brancos, todos empilhados e nesse dia tinha chovido e o chão estava todo cheio de lama e eles tinham logo à entrada da barraca tudo cheio de palha seca, uma limpeza, foi das coisas que mais me espantou."

(Técnica de serviço social numa Câmara Municipal)

Este tipo de discurso sobre uma das modalidades de apropriação do espaço surge, igualmente, quando se pretende identificar traços distintivos dos ciganos. Constata-se, pois, uma imagem contrária àquela que foi identificada no anterior estudo relativamente à manutenção de espaços de habitat mais precários. Vejamos de seguida como foi assumido o lado mais negativo da itinerância.

Como se constatou a itinerância pode assumir um sinal positivo pela sua associação à liberdade e pela sua tradução na desvinculação dos direitos de cidadania dos ciganos com a consequente desresponsabilização das entidades locais. Por outro lado, ela tende, igualmente, a assumir uma forma de desvio contra o qual a sociedade maioritária tende a lutar. As observações feitas no questionário e ao longo das entrevistas são ilustrativas de algumas práticas que visam os ciganos que circulam pelo país:
A população cigana deixou de ser nómada há muito tempo. Os que os visitam também são sedentários. As famílias residentes sabem que podem receber visitas, mas que a comunidade não pode aumentar por via da permanência de outros ciganos vindos do exterior (Questionário CTI)

A população só aceita os que se encontram no município, mais não são bem vindos (Questionário CTI)

Manifestação da população da freguesia de $\mathrm{O}$. em relação à permanência desta comunidade (Questionário CTI)

Os ciganos itinerantes passam esporadicamente, não tendo um local específico para se instalarem. Já aconteceram duas situações nas freguesias de $\mathrm{O}$. e de $\mathrm{S}$. em que os populares se manifestaram contra a aquisição de propriedade por parte de ciganos (Questionário CTI)

Eles iam às vivendas retirar água dos quintais e isso criou um problema um pouco pesado, porque depois da água levavam laranjas, depois pediam alguma camisola. Acabámos por colocar alguns pontos de água naquele espaço e que acabou por diminuir alguns destes problemas com a comunidade envolvente. De qualquer forma, naquele bairro as pessoas sempre se mostraram muito descontentes por aquela comunidade cigana estar ali, por causa das questões do gado, depois o cheiro, e tudo o mais (Entrevistas)

Quando se fixam é logo às 15 famílias, as crianças vão para a escola. E há logo reacção, a primeira reacção da comunidade é não querer as crianças na escola (Entrevistas)

Justificação dada por uma autarquia para a não construção de uma bica num Bairro onde residiam ciganos: "poderia servir para chamariz para mais ciganos, mas lá se construiu a bica (...) Os técnicos ainda avançaram com a proposta de se construírem balneários, um lavadouro, mas era sempre a velha questão de: ‘eles estão cá por pouco tempo, quanto mais condições lhe dermos pode complicar, pois pode trazer mais ciganos de fora. Isso era argumento para não se fazer nada." (Entrevistas) 
Por fim, perante casos em que se registam más condições de habitabilidade por parte de ciganos e dada a necessidade de resolver a situação, seja pelo acesso condigno a uma habitação, seja para libertar terrenos para outras funções, seja ainda para resolver problemas de coexistência, os locais para acolhimento de populações itinerantes, muitas vezes denominados de "Parques Nómadas", tendem a aparecer como uma solução aparentemente vantajosa do ponto de vista económico (construção pré-fabricada) e de ordenamento do território (zona de equipamento). E é nestas situações que os itinerantes já não pertencem aos territórios "dos outros". E se os ciganos surgem como imperativo político ou social para a sua construção o equipamento poderá vir a ser rentabilizado no caso de resolução de situações de emergência habitacional ${ }^{13}$.

\section{O Estatuto dos Locais de Permanência nos Últimos 30 anos e a Redefinição do Lugar dos Ciganos no Território}

Compreender as condições oferecidas pelos territórios por onde os ciganos circulam e permanecem e as transformações verificadas nos últimos anos revelava-se um dado importante de contextualização de determinados projectos dirigidos a populações itinerantes, ao mesmo tempo que fornecia indicadores sobre as práticas adoptadas por algumas autarquias, nomeadamente em termos das suas "respostas" ao acolhimento desta população.

Os ciganos nos últimos 30 anos permaneciam tendencialmente em terrenos públicos $(58,3 \%$ dos municípios assim o referiram). No entanto, em cerca de $1 / 3$ dos concelhos registou-se a alteração dos locais de permanência $(35,2 \%)$, sendo actualmente os terrenos privados os eleitos para a fixação temporária $(50,9 \%)$. A alteração do estatuto dos espaços ocupados pelos ciganos é por si só reveladora das modificações que se estão a produzir nos seus estilos de vida, modificações estas sobretudo desencadeadas pelas transformações das dinâmicas territoriais e pela mudança de atitudes face à gestão das questões sociais. Um aspecto aqui evi- denciado é que a urbanização tende a abalar as estruturas tradicionais da sua vida económica e social, assistindo-se a um afastamento espacial sistemático dos lugares colectivos de estatuto público, numa lógica crescente de exclusão económica, social e territorial.

Já no anterior estudo se tinha constatado que o local de estacionamento dos ciganos itinerantes em Vila Nogueira de Azeitão não foi o mesmo ao longo dos tempos, ainda que não tenha sido a transferência da feira para outro espaço que estivesse na origem das mudanças verificadas. $O$ processo de urbanização e as reclamações da população surgiram, segundo os entrevistados, como as principais causas da deslocalização dos terrenos de estacionamento dos ciganos. Estes parecem ter sido "empurrados" para a berma da Estrada Nacional 10 , ainda que procurem terrenos privados para a sua fixação. No fundo, à medida que determinados espaços foram perdendo a sua função inicial, nomeadamente agrícola, os ciganos ganharam maior visibilidade em espaços públicos mais expostos, tornando-se mais premente demarcar as fronteiras face a outros grupos sociais em presença.

Fig. 4 - Evolução do tipo de espaços eleitos pelos ciganos para permanecerem

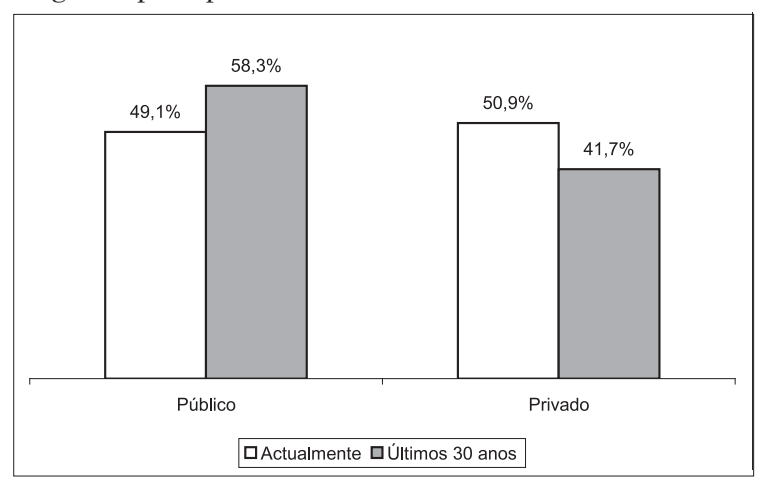

Fonte: Questionário Ciganos, Territórios e Itinerância, CET, 2005

De acordo com os resultados apurados no questionário, a mudança dos locais de permanência prende-se maioritariamente com a alteração de funções associadas a determinados espaços $(51,6 \%)$. De facto, esta tem sido também a principal razão encontrada noutros países europeus em que espaços antes deixados livres na malha urba-

\footnotetext{
${ }^{13}$ Uma das entrevistas realizadas permitiu constar que perante a ausência de um dispositivo legal sobre a definição de situações de emergência, um município elaborou um documento de apoio à decisão dos técnicos em que se prevê as seguintes situações prioritárias: indivíduo com qualquer tipo de patologia; incapacidade de aquisição própria para famílias com elementos deficientes ou menores em risco e acrescenta-se "Os ciganos só por circularem no território concelhio não têm necessariamente de estar abrangidos."
} 
na davam margem aos ciganos para aí poderem permanecer ${ }^{14}$. 38,7\% das respostas das câmaras indicam que são os próprios ciganos que optaram por outros locais e $29 \%$ apontam para o impedimento dos proprietários de terrenos em deixarem aí permanecer os ciganos. As outras situações prendem-se, sobretudo, com o realojamento dos ciganos em habitações sociais ou a extinção de barracas.

Interessava, pois, compreender as motivações dos ciganos para escolherem outros locais, quando se sabe que muitas vezes as populações locais "pressionam-nos", no sentido de estes se verem obrigados ou quase que obrigados a abandonarem o local. De facto, esta era uma hipótese de resposta contemplada, mas nenhuma câmara optou pela sua sinalização, possivelmente pela dificuldade das autarquias reconhecerem que determinados problemas de exclusão social decorrem da discriminação étnica e daí serem raras as iniciativas destinadas à população não cigana (SOS Racismo, 2001: 10). Apesar de não terem existido respostas na categoria "a população local impediu a sua permanência", como já foi possível constatar a "vigilância" e a "pressão" da população local parecem estar presentes em alguns concelhos.

Outro dado a reter prende-se com as atitudes tomadas pelas autarquias perante a existência de abaixo-assinados promovidos pelas populações locais para expulsar os ciganos dos respectivos territórios concelhios. Apenas 14 municípios $^{15}$ referiram ter-se assistido a esta prática que exige algum nível de institucionalização do incómodo, tendo cerca de metade reagido através do recurso às forças de autoridade. Algumas das respostas apontam para este tipo de intervenção estando na sua origem fundamentações de tipo diferente: "estarem a prejudicar o bem-estar do meio", quando ocorrem "desacatos entre a comunidade cigana e os utentes nómadas do concelho" ou se verifica a "permanência de acampamentos não autorizados". As restantes autarquias referem ter desempenhado um papel de mediação/conciliação, de procurar soluções para o acolhimento dos itinerantes ou simplesmente não atribuir relevância aos abaixo-assinados.
Deve também ter-se presente que o "optar" por outros locais também poderá estar relacionado, por um lado, com alterações da configuração espacial dos lugares anteriormente ocupados, deixando de se revelarem lugares aprazíveis para a permanência, mesmo que seja por um curto período de tempo. Por outro lado, com medidas "repressivas" que impedem o estacionamento/acampamento em determinados lugares do município.

Fig. 5 - Razões subjacentes à alteração dos locais de permanência dos ciganos itinerantes

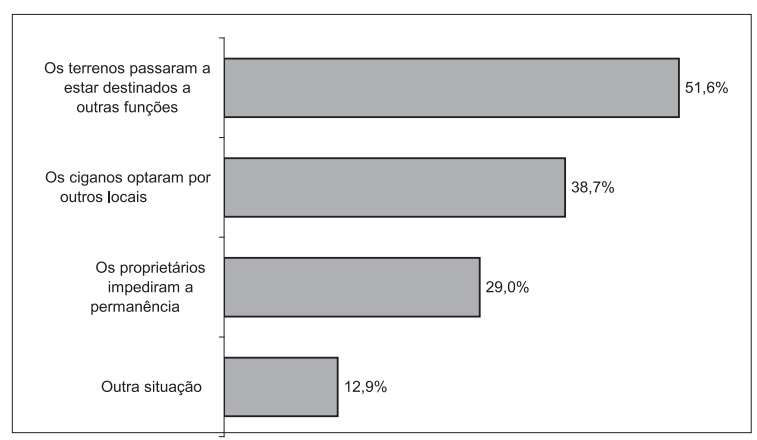

Fonte: Questionário Ciganos, Territórios e Itinerância, CET, 2005

Face à inexistência em Portugal de disposições normativas no âmbito do estacionamento de populações nómadas, a forma encontrada de regulamentar a permanência destas comunidades encontra-se expressa no DL n. ${ }^{\circ} 310 / 2002$, de 18 de Dezembro, situação curiosa quando este dispositivo legal põe no "mesmo saco" o regime jurídico do licenciamento do exercício de um conjunto de actividades muito diversas, tais como a de guarda-nocturno, venda ambulante de lotarias, arrumador de automóveis, realização de acampamentos ocasionais, exploração de máquinas de diversão, realização de fogueiras, entre outras. Este dispositivo legal vem passar para as câmaras municipais a competência em matéria de licenciamento das actividades referidas até aí cometidas aos governadores civis, nomeadamente para fins de manutenção da ordem, tranquilidade e segurança públicas, sendo possível propor ao Ministro da Administração Interna a elaboração dos regulamentos necessários à execução das leis.

Na actual legislação "a realização de acampamentos ocasionais fora dos locais adequados à prática do campismo e caravanismo fica sujeita à

\footnotetext{
14 São muito os exemplos em diversas cidades de locais que deixaram de ser ocupados pelos ciganos para darem lugar a Cidades Olímpicas (caso de Grenoble), Centro de Congressos (caso de Nantes), Exposições internacionais (caso de Lisboa), entre outros.

15 Albergaria-a-Velha, Alcobaça, Almeirim, Aveiro, Condeixa-a-Nova, Évora, Felgueiras, Fornos de Algodres, Lourinhã, Moita, Portimão, Reguengos de Monsaraz, Santarém e Vila Real de Santo António. Apenas o Gabinete do Governador Civil de Faro referiu ter conhecimento de abaixo-assinados em alguns dos concelhos do distrito, tendo encaminhado o assunto para as forças de segurança.
} 
obtenção de licença da câmara municipal, devendo ser requerida pelo responsável do acampamento e dependendo a sua concessão da autorização expressa do proprietário do prédio. A realização de qualquer acampamento ocasional fica sujeita à emissão de parecer favorável das seguintes entidades: a) Delegado de saúde; b) Comandante da PSP ou da GNR, consoante os casos. A licença é concedida por um período de tempo determinado, nunca superior ao período de tempo autorizado expressamente pelo proprietário do prédio, podendo ser revogada a qualquer momento (DL n. ${ }^{\circ} 310 /$ /2002, de 18 de Dezembro, art. $\left.^{\circ} 18 .^{\circ}\right)$.

Relembre-se que os sucessivos regulamentos da Guarda Nacional Republicana têm revelado orientações "especiais" para a comunidade cigana. O regulamento elaborado em 1920, só revogado em 1985, determinava a obrigação de registo dos ciganos, a fixação de residência, o cumprimento de serviço militar, a obrigatoriedade de vacinação e higiene e a possibilidade de concessão de "atestados de boa conduta". Um dos artigos do Regulamento de 1985 permite o exercício de vigilância especial sobre os nómadas por se entender que a sua mobilidade e carência económica favorecem as práticas criminais. Embora o Procurador-Geral da República tivesse considerado que aquela norma violava o princípio constitucional da igualdade, ela não foi revogada (Pinto, 2000: 84-85). Este regulamento só foi extinto em 1996, após a situação verificada em Vila Verde.

A não associação sistemática da tenda, carrinha e auto-caravana a modalidades de habitat poderá ser reveladora do desconhecimento político dos modos de vida da população cigana, mas poderá, sobretudo, revelar uma forma de pressão para que se abandonem estes mesmos modos de vida ou de facilitação no exercício da vigilância, nomeadamente através de visitas domiciliárias da força da ordem.

Revela-se, pois, fundamental desencadear dois tipos de reflexões. Por um lado, uma reflexão rigorosa sobre o que é um território, pois "podemo-nos arriscar a rejeitar todos aqueles que vivem em habitat-caravana ou em mobilidade como extraterrestres, constantemente excluídos dos direitos de cidadania" (Gilles, 2001: 119), como se a mo- bilidade impossibilitasse o enraizamento territorial. Embora os ciganos não reivindiquem o direito a um determinado território, eles apropriam-se de um espaço e marcam a sua presença. Por outro lado, uma reflexão sobre o lugar dos ciganos no território o que pressupõe uma compreensão dos modos de habitar das famílias e uma inversão de pontos de vista, pois as formas de ocupação do espaço por parte dos ciganos são "estranhas" aos esquemas habituais de organização da cidade e dos espaços residenciais. Esta reflexão implica, assim, considerar os espaços de mobilidade das populações ciganas tanto na sua regularidade espaço-temporal, como no dinamismo da sua mutação (Humeau, 1997: 7).

A política de acolhimento em meio urbano ou rural deveria, assim, evitar situações standardizadas e optar por uma pluralidade de soluções, capaz de preservar a autonomia e a especificidade das famílias ciganas, pois os lugares de residência devem responder a necessidades diversas em função das estratégias de inserção. Esta constatação implica reconhecer aos lugares de habitat um novo significado social e económico. E como refere Humeau a possibilidade de encontrar uma diversidade de situações passa também por identificar as necessidades quantitativas e qualitativas e a variação de escalas geográficas de detecção de necessidades. Sempre no pressuposto de que se faça a devida correspondência entre as lógicas territoriais das famílias e as formas de organização dos poderes locais (Humeau, 1997: 7).

No sentido de se compreender as medidas adoptadas pelas Câmaras Municipais perante a permanência dos ciganos em locais públicos durante mais de 48 horas, apresentam-se de seguida os resultados obtidos para 66 câmaras que responderam a esta questão. Constata-se que metade dos municípios opta por medidas "repressivas": contacta os agentes da autoridade $(31,8 \%)$, os próprios serviços municipais de fiscalização informam os ciganos para desocuparem os locais $(12,1 \%)$ e em $6,1 \%$ os ciganos são "avisados"/ "intimidados"16 a abandonar o local por uma entidade não discriminada. Por outro lado, 15,2\% argumenta que a curta permanência não justifica qualquer intervenção, pressupondo, assim, que ultrapassado o tem-

${ }^{16}$ Recuperam-se aqui as expressões dadas nas respostas. 
po considerado aceitável pelo município o mais natural será accionar as medidas já identificadas.

Cerca de $20 \%$ das autarquias refere não tomar qualquer medida, verificando-se nalgumas destas respostas a necessidade de acrescentar que a intervenção só tende a acontecer em casos de "desordem pública", de "ameaça à ordem e tranquilidade do município", quando "causam distúrbios", perante "situações anormais". Estas expressões são reveladoras da existência de situações conflituosas, latentes ou manifestas, em que os ciganos tendem a ser os seus promotores.

Fig. 6 - Medidas adoptadas pelas Câmaras Municipais perante a permanência dos ciganos em locais públicos durante mais de 48 horas

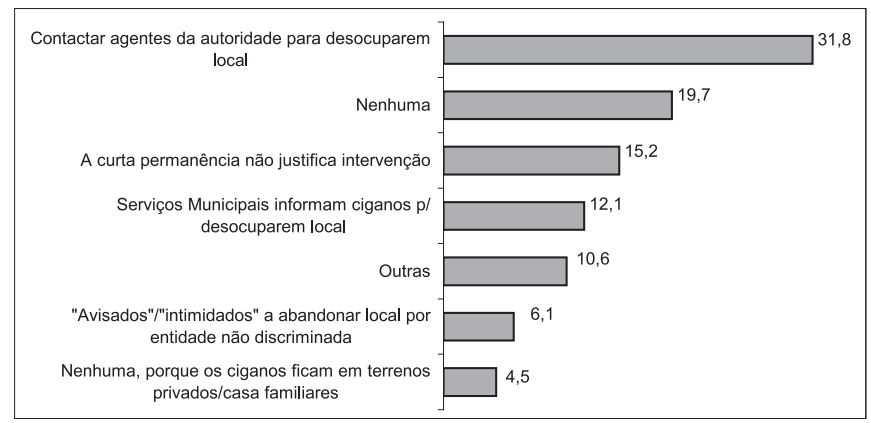

Fonte: Questionário Ciganos, Territórios e Itinerância, CET, 2005

Algumas observações registadas no questionário permitiram constatar a existência de outro tipo de práticas:

- de vigilância ${ }^{17}$, decorrentes da legislação em vigor acima mencionada:

"A população reclama e a autarquia comunica tal facto à PSP"

“Antes era o Governo Civil que passava as licenças de permanência, agora passou para a autarquia e está a ser feita uma fiscalização muito rigorosa junto desta comunidade, no sentido de terem que solicitar à autarquia essa licença, e só podem permanecer no concelho pelo período máximo de 3 dias"

- de vigilância, não decorrentes da legislação, que se constituem informalmente como um entrave administrativo à circulação. É o caso de um município que exige o cartão de vendedor ambulante actualizado quando os ciganos pretendem prenoitar no concelho;

- de estabilização administrativa que tendem a incentivar o retorno dos ciganos ao "concelho de origem" com o intuito destes declararem um domicílio para o exercício de certos direitos. Nestas situações o raio de deslocação tende a ser menor, tornando mais fácil a vigilância:

"A câmara contacta as autoridades para que estas procedam ao encaminhamento dos ciganos para outros locais"

"Informa-os de que têm de regressar ao concelho de origem"

"São tomadas medidas apenas em casos de "crianças em perigo" nomeadamente a articulação com os serviços locais de segurança social, "no sentido de regressarem aos concelhos de residência"

- reguladoras da duração de permanência, não se tendo registado nenhuma resposta por um período superior a três dias.

As outras respostas apontam para situações também diversificadas, no entanto, as atitudes não tendem a ser tão implicitamente discriminatórias, nomeadamente por se manifestar o envolvimento dos ciganos nas acções que são tomadas. Assim, é possível constatar a existência de práticas que assentam:

- na especificidade dos locais eleitos pelos ciganos para a permanência:

"As medidas são diferenciadas em função dos locais onde acampam"

- nas necessidades e expectativas dos ciganos, especialmente no que respeita à habitação:

"A PSP identifica as famílias para que a Câmara consiga detectar as suas necessidades"

"Perante o carácter permanente da ocupação equaciona-se o realojamento"

\footnotetext{
${ }_{17}$ Noutros países europeus estas medidas de vigilância podem assumir formas diversas como por exemplo a exigência de documentos para circular (Itália, Holanda, Reino Unido), controlos periódicos das deslocações (Bélgica, Croácia, Itália), obrigatoriedade de se apresentarem às autoridades (Itália, França).
} 
- no envolvimento de representantes de entidades locais (assentes no Conselho Municipal de Segurança ${ }^{18}$ ) e de representantes da comunidade cigana residentes numa freguesia de um concelho do país. Este envolvimento concretizou-se, no caso de um município, através de um "Acordo Sobre Regras de Comportamento da Comunidade Cigana". A sua concretização é justificada pelo facto das famílias ciganas aí residentes terem "levantado algumas questões de segurança na freguesia". O cumprimento do referido acordo por parte dos ciganos "abre a hipótese de obtenção futura de melhores condições de habitabilidade", já o "não cumprimentos destas regras básicas implica o cancelamento do processo do Rendimento Mínimo Garantido"

O princípio do acordo acima referido envolvimento de toda a comunidade - embora se revele uma intenção positiva, acaba por ser discricionária, na medida em que metade das ditas "regras básicas" não eram motivo de cancelamento da prestação do RMG, nem são do RSI ${ }^{19}$ nomeadamente as que indicam:

- "Não permitir a permanência de familiares e amigos por um período superior a 3 dias (salvo raras excepções comunicadas atempadamente)";

- "Manter o espaço envolvente ao acampamento devidamente limpo e arrumado";

- "Aquando da utilização dos lavadouros devem limitar-se apenas ao tanque de lavagem. Não podem deixar roupa espalhada, nem outros lixos, não devem colocar as bicicletas dentro do tanque nem outro tipo de objectos".

\section{As áreas de acolhimento: uma resposta inovadora à problemática da habitação para populações desfavorecidas ou um direito dos itinerantes?}

O projecto de investigação recentemente concluído permitiu aprofundar dois projectos, ainda numa fase inicial de desenvolvimento, que procuram responder a um problema habitacional e de coexistência em que se encontra envolvida a população cigana, sob o pretexto de se estarem a construir áreas para acolhimento de populações itinerantes $^{20}$. A incursão por estas estruturas levanta alguns questionamentos em torno das modalidades de criação destas áreas, das suas formas de gestão e sustentabilidade, bem como das condições de acesso e de ocupação que são impostas. A reflexão sobre estas questões e o acompanhamento futuro do desenvolvimento destes projectos torna-se relevante para a eventualidade de se vir a equacionar a extensão destas práticas a outros municípios ou mesmo para a possibilidade do Estado (ou da administração central) poder ter um papel relevante nesta matéria, nomeadamente em termos legislativos. Referimo-nos aqui a esta tendência, uma vez que tem sido a prática em alguns países europeus.

Podemos mencionar a título de exemplo os casos de França, Itália e Reino Unido. No primeiro, o enquadramento legal relativo ao acolhimento e ao habitat das populações itinerantes (Lei n. ${ }^{0} 2000$ -614, de 5 Julho de 2000, dita Lei Besson) obriga os municípios com mais de 5000 habitantes a implementar áreas de acolhimento para evitar o estacionamento "selvagem". A filosofia geral deste novo dispositivo legal visa equilibrar direitos e deveres, preservar os direitos dos municípios e dos seus habitantes em caso de ocupação ilícita de terrenos e respeitar um habitat condigno às populações nómadas. Em Itália, nos anos 70, o Ministro do Interior emitiu uma circular convidando os presidentes de câmara a suprimirem as interdições de estacionar destinadas aos nómadas. Desde os anos 80, dez das vinte regiões italianas e uma província legislaram a favor dos nómadas, reconhecendo o direito ao nomadismo, ou seja, ao estacionamento e definindo dois tipos de áreas, cuja construção foi deixada às autoridades locais: áreas de perma-

\footnotetext{
${ }^{18}$ A Lei n. ${ }^{\circ}$ 33/98, de 18 de Julho veio criar os Conselhos Municipais de Segurança qualificando-os de entidades de âmbito municipal com natureza consultiva, articulação, informação e cooperação ( $\operatorname{art}^{\circ}{ }^{\circ} .^{\circ}$ ). Entre os seus objectivos encontra-se a formulação de propostas de solução para os problemas de marginalidade e segurança dos cidadãos do respectivo município e a promoção da discussão sobre medidas de combate à criminalidade e à exclusão social (art. ${ }^{\circ} 3 .^{\circ}$, alínea b e c)

19 A entrada em vigor da Lei n. ${ }^{\circ} 13 / 2003$, de 21 de Maio veio revogar o Rendimento Mínimo Garantido e criar o Rendimento Social de Inserção. A regulamentação da nova medida encontra-se expressa no DL n. ${ }^{\circ} 283 / 2003$, de 8 de Novembro.

${ }^{20}$ Das 43 câmaras municipais que responderam ao questionário CTI e conseguiram identificar o peso de ciganos itinerantes, apenas 13 equacionaram já a possibilidade de construir um local específico para acolher populações itinerantes, foram eles: Beja, Cascais, Coimbra Elvas, Évora, Monforte, Paços de Ferreira, Reguengos de Monsaraz, Santarém, Vidigueira, Vila Nova de Gaia, Vila Real de Santo António e Vila Viçosa. Apenas Beja, Coimbra e Vila Viçosa acabaram por concretizar a ideia, embora nem sempre nos moldes que inicialmente o projecto tinha sido pensado.
} 
nência e áreas de trânsito. No Reino Unido, a lei de 1994 (Criminal Justice and Public Order Act, 1994) retira a obrigação de criação de áreas (secção 80, do Caravan Sites Act, 1968), mas mantiveram-se ou alargaram-se as interdições de estacionar (ex.: proibido estacionar perto de uma auto-estrada, e em terrenos sem autorização do proprietário), aumentando-se também as competências das autoridades locais para retirar as pessoas de certos sítios.

As modalidades de criação das áreas de acolhimento para itinerantes (independentemente de quem seria o seu promotor) não estão isentas de repercussões ao nível dos modos de vida da população cigana, uma vez que se tende a passar da existência de um direito a que determinadas populações itinerantes podem usufruir para a obrigatoriedade de se ter de fazer as paragens possíveis, dada a existência de sanções associadas ao estacionamento irregular. Neste último caso, se as áreas forem em número insuficiente não haverá outra alternativa a não ser a permanência fora das áreas previstas para o efeito com a tendência para se reduzir a livre circulação/estacionamento e aumentar os processos de sedentarização. Perante a escassez de espaços urbanos para se poder estacionar tendem também a crescer os problemas associados à perturbação da ordem pública, onde geralmente sobressaem as preocupações de carácter higienista.

O aparecimento de áreas específicas para acolher populações nómadas vem, pois, limitar as possibilidades de estacionamento espontâneo (dito "selvagem"). No plano das intenções, estes espaços procuram aumentar a qualidade de vida daqueles que os frequentam, no entanto, também contribuem para a produção de determinada imagem exterior. Num tecido urbano cada vez mais denso e regulamentado a escolha para a implementação destas áreas é, muitas vezes, canalizada para “espaços territoriais marginais" (proximidade de uma linha ferroviária, da auto-estrada, de estações de tratamento de águas e resíduos...), conduzindo à determinação de percepções exteriores negativas e a processos de estigmatização (à mobilidade associa-se facilmente pobreza e precariedade).
Ficou, de facto, patente a dificuldade com que se confrontaram ou ainda confrontam vários municípios para encontrarem espaços disponíveis para concretizarem o projecto, sobretudo, pelas resistências encontradas por parte de proprietários de terrenos que serviriam este propósito, mas também pelas reacções da própria população que tende a recusar a presença dos ciganos na proximidade do seu local de residência. Assim, os locais encontrados tendem a ser periféricos face às centralidades urbanas, justificando-se a sua localização perante a enorme vantagem de evitar problemas de coexistência.

Delinear as condições de acesso e de ocupação das áreas de acolhimento merece, igualmente, muitas cautelas face à especificidade da população que se pretende acolher. Existem situações sociais muito diferenciadas que poderão reunir as condições de acesso aos ditos "Parques Nómadas", colocando-se mais uma vez o problema da coexistência quando à proximidade física não corresponde necessariamente uma proximidade social. Estes espaços regulamentados de permanência podem ainda simbolizar o lugar atribuído pela sociedade dominante a determinados grupos. Estes lugares só podem ser recusados, pois a vida colectiva como resultado de uma afectação administrativa, e não de uma livre escolha, raramente resultou, tanto para sedentários como para nómadas. Fixar a duração da permanência não está na "mentalidade" dos nómadas. Ela parte da lógica da gestão territorializada da pobreza, que pretende que cada município faça a gestão dos seus pobres numa lógica de fixação de trajectórias de áreas em áreas. Não se está, assim, a aceitar o nomadismo, mas a desenhar-se o seu perímetro de deambulação (Assier e Gotman, 2003: 226). "Convidam-se", assim, os ciganos a optar por condições de vida consideradas "moralmente aceitáveis" e apela-se ao seu sedentarismo ${ }^{21}$.

A implantação espacial de estruturas de acolhimento para populações nómadas deveria, no entanto, implicar para além de uma preocupação de inserção social, através das diferentes dimensões de que os indivíduos podem estar excluídos (profissional, económica, habitacional, saúde, educa-

\footnotetext{
${ }^{21}$ Numa avaliação sobre os terrenos de estacionamento em algumas regiões francesas Assier e Gotman (2003) fazem notar que o cepticismo dos presidentes de Câmara em instalarem os terrenos de estacionamento nos seus territórios, leva-os a acreditarem que a recusa dos nómadas em se instalarem nas áreas de acolhimento reside em traços da sua natureza, não vendo, assim, na rejeição destas áreas as faltas de condições de habitabilidade pela sua concepção, localização ou degradação. Os ciganos referem-se a estas áreas como "campos Besson”, "campos nazis". Os campos designam áreas fechadas onde os indivíduos seleccionados estão autoritariamente afectos.
} 
ção...), também uma preocupação urbanística que conseguisse assegurar as condições de partilha social, pois na ausência de contactos o "fantasma e o imaginário do outro" tendem a preencher o vazio relacional.

No caso da vertente da inserção, ou melhor da gestão dos processos de inserção, os resultados deste estudo demonstram a importância que esta assume para garantir uma maior autonomia das famílias dos serviços de protecção social, sobretudo, quando as formas de gestão implementadas permitem um acompanhamento social muito próximo e continuado e quando a parceria consegue identificar os problemas e propor respostas inovadoras e ajustadas à população em causa. Fica, no entanto, por saber se a longo prazo estas práticas terão continuidade, pois por um lado a alteração da natureza do projecto poderá comprometer algumas das acções e, por outro lado, a sustentabilidade financeira também deverá ser garantida, no sentido de não ser apenas uma entidade a disponibilizar os recursos para a sua gestão.

Relativamente à vertente urbanística colocam-se as questões da localização espacial destas áreas, pois quando não existe a possibilidade do encontro, conhece-se o outro através de estereótipos. O declínio dos "lugares de compromisso de civilidades" é um dos problemas da vida urbana actual, na medida em que estes espaços se estruturam sobre especializações funcionais, sem desenvolvimento de sociabilidades conexas (Remy, 1998: 183-184). Como refere Agier quando existem fronteiras rígidas impostas entre os cidadãos e se constata a impossibilidade de estabelecer contactos nos lugares públicos, pode assistir-se a determinadas formas de confronto. No caso concreto dos ciganos podemos assistir, por um lado, ao desenvolvimento de estratégias individuais traduzidas pela necessidade de cada um se demarcar dos estigmas associados a certos espaços, representando, muitas vezes a atitude mais atomizada e sem defesa, muito próxima do medo e da violência e, por outro lado, à fuga na procura de soluções noutros lugares, recorrendo-se à perpetuação da viagem com consequências ao nível da criação de novas formas de urbanização e de inserção nas cidades de chegada (Agier, 1999: 87-88).

Alguns autores têm reflectido sobre a importância dos espaços intersticiais na promoção da urbanidade. Ascher, por exemplo, refere a necessi- dade, na actual configuração "metapolitana", da existência de espaços específicos - espaços comunitários do "entre nós" - para determinadas comunidades desenvolverem as suas práticas, isto no pressuposto de que "se quer evitar que não sejam reprimidas ou que, ao contrário, não constituam factores de exclusão ou de conflitos" (Ascher, 1998:177). Remy, por seu lado, menciona que a separação espacial não é, em todas as circunstâncias função de exclusão, marginalização ou de isolamento por relação a uma rede de trocas. No entanto, a cidade deve compor, em escalas espaciais diferentes, lugares de separação e de agregação. A partir desta composição instaura um regime complexo de distância-proximidade variável. Assim, a urbanidade, como forma de sociabilidade, torna-se expressão de uma relação de negociações ou de transacções sociais entre protagonistas com recursos e oportunidades desiguais. A distância é, em determinadas situações, condição de comunicação e de alargamento da zona de trocas e de cooperação. Um dos significados da morfologia urbana é dar um suporte interaccional a este modo de coexistência entre entidades que não se misturam espacialmente, pelo menos para todos os aspectos da sua vida quotidiana (Remy, 1998:173).

Criar estes espaços intersticiais em meio urbano é pois uma opção política que implica reconhecer a existência de determinadas especificidades da população, conhecer os seus modos de vida e afastar o "fantasma" do diferente. Como constatámos a itinerância tende a assumir no discurso dos entrevistados traços positivos ou negativos consoante o tipo de preocupações que prevalecem face à gestão sócio-territorial. É ela ou mais concretamente os ciganos que justificam a criação de tais áreas. No entanto, a solução encontrada afasta-se das soluções standardizadas. Por um lado, tende a garantir o acesso condigno a uma habitação, libertar terrenos para outras funções, ou resolver problemas de coexistência. Por outro lado, também aparece como uma solução aparentemente vantajosa do ponto de vista económico (construção pré-fabricada) e de ordenamento do território (zona de equipamento). Fica, pois, por saber se o desenvolvimento destes projectos poderão vir a resolver as dificuldades cada vez maiores com que se defrontam os itinerantes, ou se a existência de "Parques Nómadas" é para os ciganos que se instalaram há décadas em habitações precárias. 


\section{Bibliografia}

AGIER, M.,1999, L'invention de la ville. Banlieus, townships, invasions et favelas, Paris, Ed. des Archives contemporaines.

ASCHER, F.,1998, Metapólis. Acerca do futuro da cidade, Oeiras, Celta.

ASSIER-ANDRIEU, L.; GOTTMAN, A. (coord.), 2003, Légiférer sur les 'gens du voyage'. Génese et mise en oeuvre d'une législation, Centre d'Études Politiques de l'Europe Latine, Université de Montpellier 1.

COMISSÃO EUROPEIA, 2004, La situation des rom dans une union européenne élargie, Luxemburgo, Direction générale de l'emploi et des affaires sociales.

CASTRO, A.,1995, “Ciganos e Habitat: Entre a Itinerância e a Fixação", Sociologia, Problemas e Práticas, n. ${ }^{\circ} 17$, pp.97$-111$.

DUARTE, I. (coord.) et al, 2000. Coexistência inter-étnica, espaços e representações sociais, CET/FCT, Relatório de Investigação, Dezembro (Policopiado).

GILLES, M.,2001, "Nous, on a toujours les pieds quelque part! - voyage et territoire", Études Tsiganes, Vol. 15.

HUMEAU, J. B,1997, "Place des tsiganes dans la ville", Territoires, n. ${ }^{\circ} 381$, pp. 7-8.
MARQUES, C.; CORREIA, J.; REIS, M. F., 1996, Comunidade Cigana na Diocese de Lisboa, Lisboa, Secretariado Diocesano de Lisboa Obra Nacional para a Pastoral dos Ciganos/Departamento de Acção Social da Câmara Municipal de Lisboa.

MACHIELS, T., 2002, Garder la distance ou saisir les chances. Roms et gens du voyage en europe occidentale, Réseau Européen contre le Racisme.

PINTO, M. F., 2000, A Cigarra e a Formiga. Contributos para a Reflexão sobre o Entrosamento da Minoria Étnica Cigana na Sociedade Portuguesa, Porto, Cadernos REAPN.

REMY, J.,1998, Sociologie urbaine et rurale. L'espace el l'agir. Entretiens et textes preséntés par Étienne Leclercq, Paris, L'Harmattan.

SAMA, S., 2003, "La movilidad como forma de vida en la comunidad gitana de Évora: mitos e realidades" in BRANCO, J. F. e AFONSO, A.I. (org.) Retóricas sem Fronteiras, 1/ /Mobilidades, Oeiras, Celta.

SAN-ROMAN, T.,1997, La diferencia inquietante. Viejas $e$ nuevas estrategias culturales de los gitanos, Madrid, Silo XXI.

SOS RACISMO, 2001, Ciganos, Números, Abordagens e Realidades, Lisboa, SOS Racismo.

STEINBERGER, D.; KELLER, L., 2002, La circulation des voyageurs dans les pays membres du Conseil de l'Europe, Strasbourg, MG-S-Rom. 